\title{
Corrigendum
}

\section{Corrigendum to "Development and Application of a ZigBee-Based Building Energy Monitoring and Control System"}

\author{
Changhai Peng ${ }^{1,2,3}$ and Kun Qian ${ }^{4}$ \\ ${ }^{1}$ School of Architecture, Southeast University, Nanjing 210096, China \\ ${ }^{2}$ Key Laboratory of Urban and Architectural Heritage Conservation (Southeast University), Ministry of Education, \\ Nanjing 210096, China \\ ${ }^{3}$ IIUSE, Southeast University, Nanjing 210096, China \\ ${ }^{4}$ School of Automation, Southeast University, Nanjing 210096, China
}

Correspondence should be addressed to Changhai Peng; pengchanghai@foxmail.com

Received 24 May 2017; Accepted 11 June 2017; Published 12 July 2017

Copyright (C) 2017 Changhai Peng and Kun Qian. This is an open access article distributed under the Creative Commons Attribution License, which permits unrestricted use, distribution, and reproduction in any medium, provided the original work is properly cited.

In the article titled "Development and Application of a ZigBee-Based Building Energy Monitoring and Control System" [1], the authors based their article on two of their previous publications $[2,3]$ that are not cited. The four numbered items in the section titled "5. Application of ZBEMCS" in our article [1] are reproduced from the section titled "3.1. Classification and Subentry Metering of the BEEMS" in article [2].

Additionally, there are three figures in article [1] that are taken from the previous publications [2,3], where Figures 17 and 18 correspond to Figures 5 and 6 in article [2], respectively, and Figure 14 is the same as Figure 5 in article [3].

\section{References}

[1] C. Peng and K. Qian, "Development and application of a ZigBee-based building energy monitoring and control system," The Scientific World Journal, vol. 2014, Article ID 528410, 13 pages, 2014.

[2] C. H. Peng and Y. J. Mu, "Case study of building energy and environment management system on campus: A report from Southeast University," Advanced Materials Research, vol. 860-863, pp. 1316-1322, 2014.

[3] K. Qian, X. Ma, C. Peng, Q. Ju, and M. Xu, "A zigbee-based building energy and environment monitoring system integrated with campus GIS," International Journal of Smart Home, vol. 8, no. 2, pp. 107-114, 2014. 


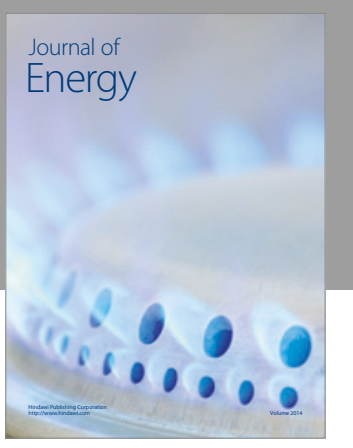

Journal of

Industrial Engineering
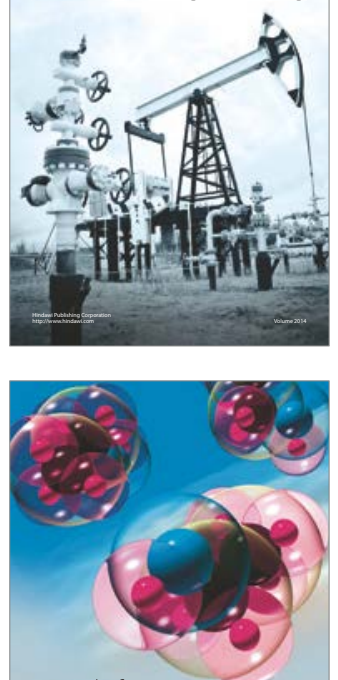

Fuels
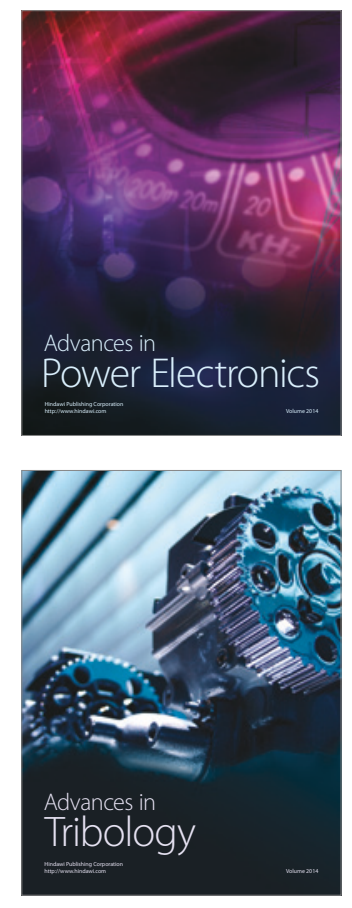
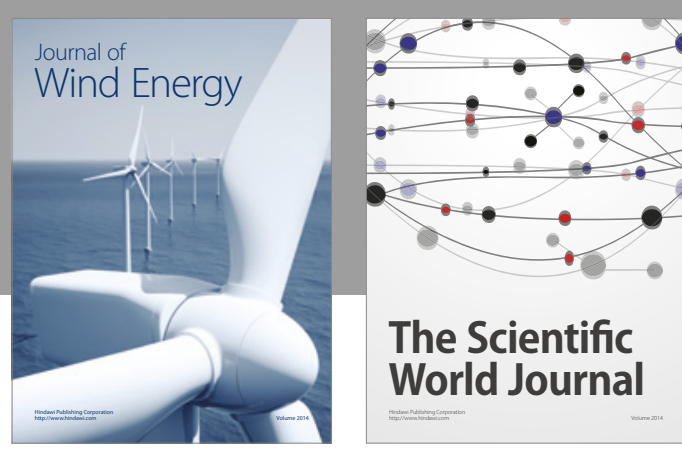

The Scientific World Journal
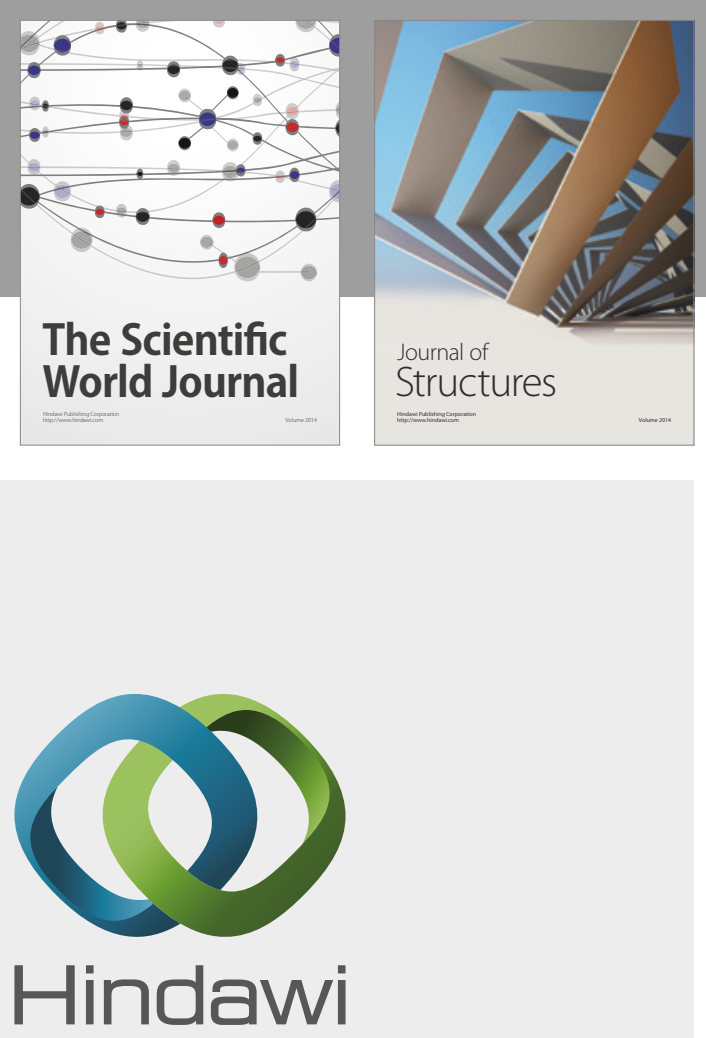

Submit your manuscripts at

https://www.hindawi.com
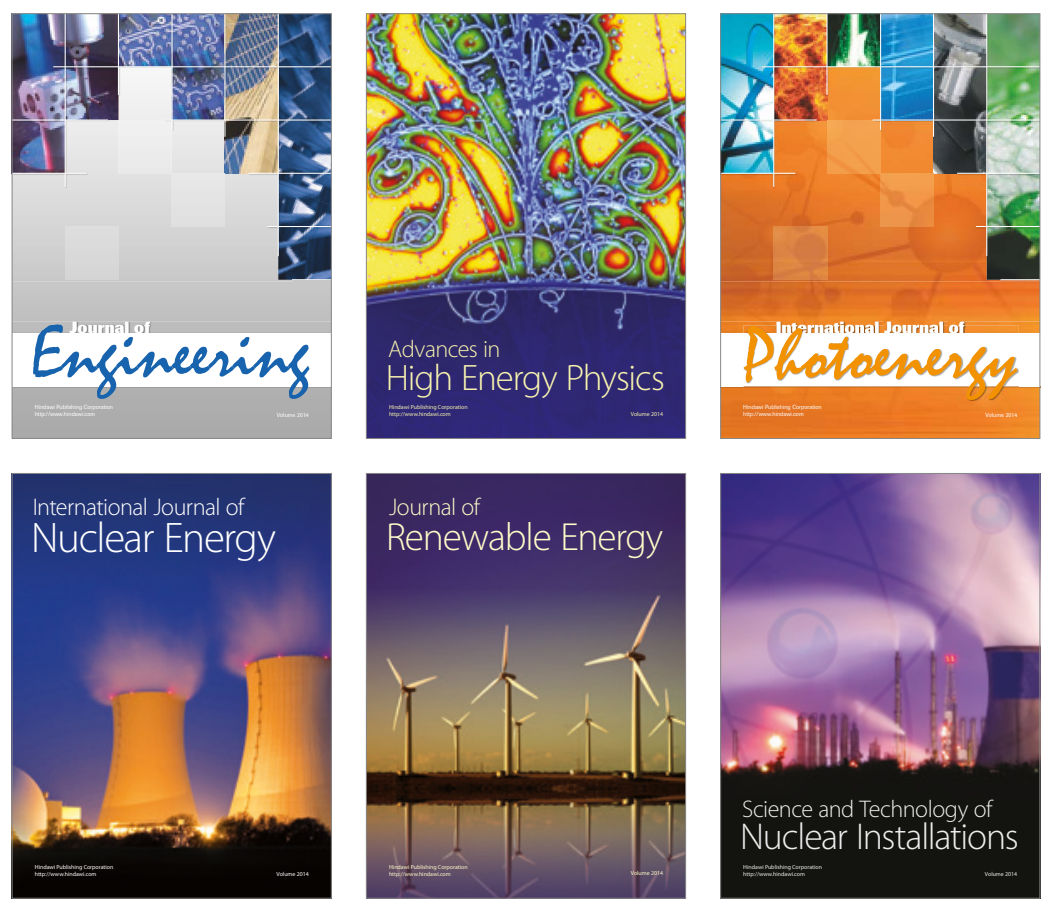

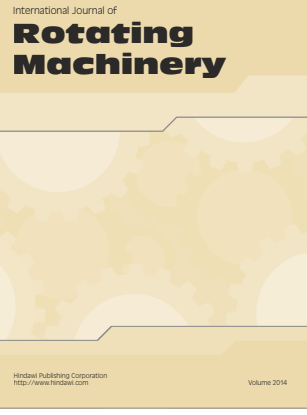

Journal of

Petroleum Engineering



Journal of
Solar Energy
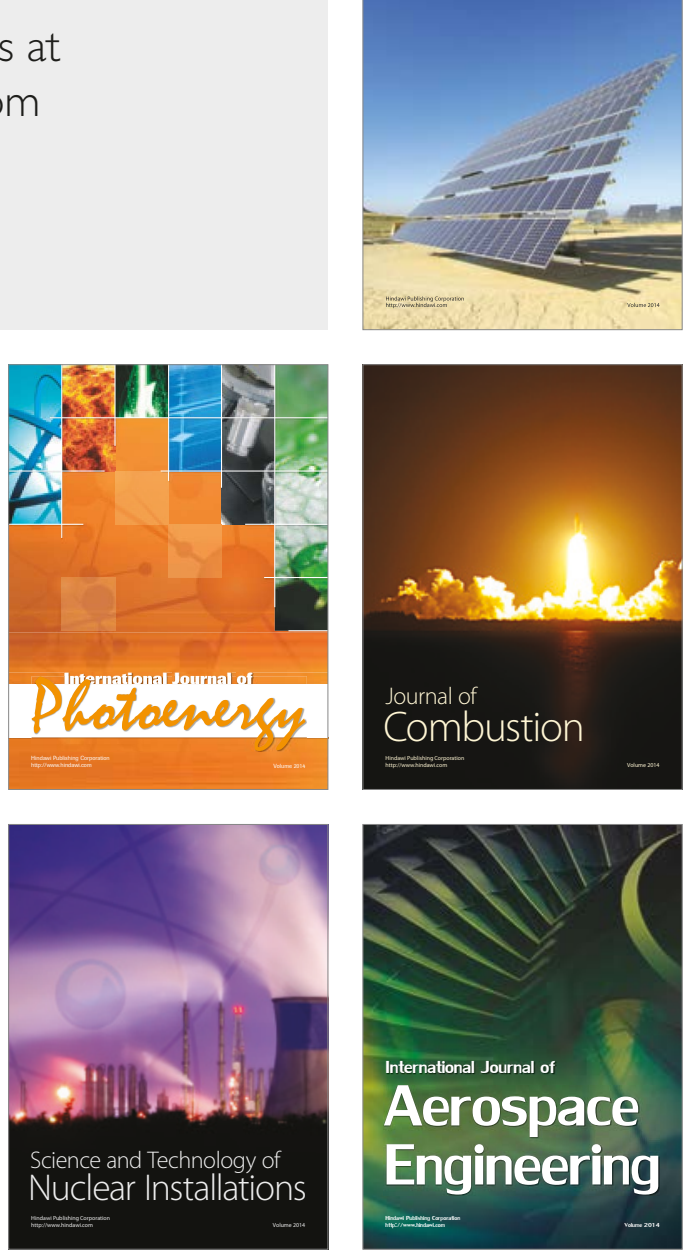